\title{
Electrochemical Detection of Phenanthrene Using Nickel Oxide Doped PANI Nanofiber Based Modified Electrodes
}

\author{
Omolola E. Fayemi, ${ }^{1,2}$ Abolanle S. Adekunle, ${ }^{1,2,3}$ and Eno E. Ebenso ${ }^{1,2}$ \\ ${ }^{1}$ Department of Chemistry, School of Mathematics and Physical Sciences, Faculty of Agriculture, Science and Technology, \\ North-West University, Mafikeng Campus, Private Bag X2046, Mmabatho 2735, South Africa \\ ${ }^{2}$ Material Science Innovation and Modelling (MaSIM) Research Focus Area, Faculty of Agriculture, Science and Technology, \\ North-West University, Mafikeng Campus, Private Bag X2046, Mmabatho 2735, South Africa \\ ${ }^{3}$ Department of Chemistry, Obafemi Awolowo University, Ile-Ife, Nigeria \\ Correspondence should be addressed to Eno E. Ebenso; eno.ebenso@nwu.ac.za
}

Received 10 November 2015; Accepted 6 January 2016

Academic Editor: Domenico Acierno

Copyright (C) 2016 Omolola E. Fayemi et al. This is an open access article distributed under the Creative Commons Attribution License, which permits unrestricted use, distribution, and reproduction in any medium, provided the original work is properly cited.

A nickel oxide doped polyaniline nanofibers (PANI-NiO) based electrochemical sensor was constructed for detection of phenanthrene. Successful synthesis of PANI-NiO nanocomposite was confirmed with techniques such as SEM, XRD, EDX, FTIR, and UV-visible spectroscopy. The electrocatalytic oxidation of phenanthrene on PANI-NiO on modified glassy carbon electrode (GCE-PANI-NiO) was studied using cyclic voltammetry, square wave voltammetry, and impedance spectroscopy and discussed. Results showed that detection of phenanthrene was enhanced by the nanostructure of PANI-NiO film. The square wave voltammetry analysis shows a very low detection limit of $0.732 \mathrm{pM}$ for phenanthrene with the linear range of $7.6 \mathrm{pM}-1.4 \times 10^{-11} \mathrm{M}$. The Tafel value of $227 \mathrm{mVdec}^{-1}$ suggests adsorption of phenanthrene oxidation intermediates on the GCE-PANI-NiO electrode. The GCE-PANI-NiO modified electrodes gave better performance towards phenanthrene in terms of current response, oxidation potential, current recovery, stability, and resistance to electrode fouling effects.

\section{Introduction}

One-dimensional nanowires are of interest for fundamental physics and application as interconnects, functional devices, and molecular sensors. Devices have been fabricated from semiconductors, metals, and carbon nanotubes, and most recently electronic conducting polymer. Polymer-based nanodevices should have advantages of low cost and flexible, controlled chemistry [1]. Electrochemically conductive polymers such as polyaniline, polypyrrole, and polythiophene have been intensively studied due to their potential applications in electronic, electroluminescence, and photoelectrochemical devices as well as in analytical chemistry [2]. In recent years, many research works have focused on the nanostructures of PANI instead of the traditional PANI because nanostructural PANI has properties such as high conductivity, large surface area, easy preparation, good environmental stability, and extensive applications which can be used in electrochemical sensors [3]. Different methods used to fabricate polyaniline nanofibers include electrospinning [4], ultrasonic irradiation [5], hard templates [6], soft template [7], interfacial polymerization [8], and seeding polymerization [9]. Among these methods, interfacial polymerization has achieved more attention due to its easiness, large-scale production ability, and environmentally benign nature. Furthermore, it has a capability to produce high-quality polyaniline nanofibers with control of their morphology, size, and diameter [10]. The synthesis route is based on the classic chemical oxidative polymerization of aniline, but instead of using the traditional homogeneous aqueous solution of aniline, acid, and oxidant, the polymerization is performed in an immiscible, organic-aqueous, two-phase system. This synthetic method yields polyaniline nanofibers with nearly uniform diameters between 30 and $120 \mathrm{~nm}$ with lengths varying from $500 \mathrm{~nm}$ to several microns [11]. Amperometric enzyme biosensors based on PANI nanoparticles have been reported [12]. Glucose 
biosensors based on Prussian blue and PANI-GOD (i.e., PANI-glucose oxidase) modified electrodes have also been developed [13]. Langer et al. have developed a choline sensor by immobilization of choline oxidase to nanoporous PANI layers [14]. Considering the technological promises of PANI at nanoscale level, its application as electrochemical sensors has been reported [11, 15-18].

The search for effective method in the determination and quantifications of contaminants in the environment has been a great concern in the heart of researchers. Pollutionfree environment is truly the desire of everyone. PAHs are among the organic pollutants that have been identified as teratogenic, mutagenic, and carcinogenic in nature [19]. They have dangerous effects on both aquatic organisms and human beings through natural and anthropogenic activities, which are generated from industrial, agricultural, and domestic waste. Examples of the PAHs are anthracene, phenanthrene, fluoranthene, and pyrene [20,21].

On the other hand, nickel oxide $(\mathrm{NiO})$ is an important transition metal oxide with cubic lattice structure. It has attracted a variety of applications such as in catalysis [22], battery cathodes [23, 24], gas sensors [25], electrochromic films [26], and magnetic materials [27]. It possesses anodic electrochromism, excellent durability and electrochemical stability, large spin optical density, and various manufacturing possibilities [28].

We have been motivated to embark on this study by a number of reasons: (i) the easy synthesis and availability of nickel oxide ( $\mathrm{NiO}$ ), (ii) anticipated enhanced electrocatalysis due to the electronic interaction between the $\mathrm{NiO}$ nanoparticles and PANI nanofibers; (iii) the work of Tovide et al. [19] that showed that Graphenated polyanilinedoped tungsten oxide nanocomposite can determine phenanthrene at picomolar concentration; (iv) the existence of a dearth of information on the use of PANI nanofiber towards oxidation of phenanthrene; and (v) recent work from our group that showed that nanocomposite of metal oxide nanoparticles with nanoporous carbon based materials can detect environmental analyte such as nitrite at low potential, high current response, and with good sensitivity [29].

In this work, we studied an electrochemical sensor for detection of phenanthrene by using glassy carbon electrode modified with PANI nanofibers doped with nickel oxides nanoparticles (GCE-PANI-NiO electrode). The nanocomposites were characterized with field emission scanning electron microscope (FE-SEM) and electrochemical impedance spectroscopy (EIS) measurements. Also, the electrocatalytic behaviours of the modified electrode towards the detection of phenanthrene were evaluated by cyclic voltammetry $(\mathrm{CV})$ and square wave voltammetry (SWV). We show that the fabrication of this electrode is simple and, more importantly, provides well-defined voltammograms for catalytic detection of phenanthrene, as well as stable and resistant to electrode fouling effect. We also demonstrated that PANI-NiO layers on the GCE-PANI$\mathrm{NiO}$ electrode greatly impact on the phenanthrene current response.

\section{Experimental}

2.1. Reagents. Aniline $\left(\mathrm{C}_{6} \mathrm{H}_{5} \mathrm{NH}_{2}\right)$, ammonium persulfate $\left(\left(\mathrm{NH}_{4}\right)_{2} \mathrm{~S}_{2} \mathrm{O}_{8}, \mathrm{APS}\right)$, hydrochloric acid $(\mathrm{HCl})$, and $\mathrm{Ni}\left(\mathrm{NO}_{3}\right)_{2}$. $6 \mathrm{H}_{2} \mathrm{O}$ were obtained from Sigma Aldrich and they were all used as received. All other chemicals used in the experiments were of analytical grade, and all solutions were prepared using deionized water. All electrochemical measurements were performed at ambient temperature.

2.2. Apparatus. All electrochemical measurements were carried out using AUTOLAB Potentiostat PGSTAT 302 (Eco Chemie, Utrecht, The Netherlands) driven by the GPES software version 4.9 in an electrochemical workstation consisting of three-electrode system, a glassy carbon electrode (GCE) as the working electrode, a silver/silver chloride electrode $(\mathrm{Ag} / \mathrm{AgCl}$, sat'd $\mathrm{KCl})$ as the reference electrode, and a platinum $(\mathrm{Pt})$ wire as the counter electrode. Electrochemical impedance spectroscopy (EIS) measurements were performed with AUTOLAB Frequency Response Analyser (FRA) software between $1.0 \mathrm{~Hz}$ and $10 \mathrm{kHz}$ using a $5 \mathrm{mV}$ rms sinusoidal modulation with a solution of $1 \mathrm{M} \mathrm{HCl}$. A bench top $\mathrm{pH} / \mathrm{ISE}$ ORION meter, model $420 \mathrm{~A}$, was used for $\mathrm{pH}$ measurements. All solutions were deaerated by bubbling nitrogen prior to each electrochemical experiment. Experiments were performed at $25 \pm 1^{\circ} \mathrm{C}$. UV-Vis absorption spectra were recorded by a UV-1901 UV-Vis spectrophotometer (Agilent Technology, Cary series UV-Vis spectrometer, USA) using quartz cell with the path length of $1.0 \mathrm{~cm}$. FTIR experiments were performed using Fourier transformed infrared spectrophotometer (Agilent Technology, Cary 600 series FTIR spectrometer, USA). The transmission electron microscopy (TEM) experiment was performed using a Tecnai G2 Spirit FEI (USA) and scanning electron microscope (SEM, JEOL-JSM-6700F), respectively, was used to characterize the chemical change and morphology of the synthesised nanomaterials.

2.3. Synthesis of Nanomaterials. Polyaniline nanofibers (PANI) were synthesized according to the procedure reported in literature [30]. $0.298 \mathrm{~g}$ aniline was added to $10 \mathrm{~mL}$ of $1.0 \mathrm{M} \mathrm{HCl}$ aqueous solution. $0.186 \mathrm{~g}$ APS was dissolved in $10 \mathrm{~mL}$ of $1.0 \mathrm{M} \mathrm{HCl}$ aqueous solution. The initiator solution (APS in $1.0 \mathrm{M} \mathrm{HCl}$ ) was added into the monomer solution (aniline in $1.0 \mathrm{M} \mathrm{HCl}$ ) all at once. The initial ratio of APS/aniline was 1:4. The polymerization reaction was carried out under static conditions for $10 \mathrm{~min}$ at room temperature. The resulting polyaniline precipitate was filtered, washed with deionized water several times, and dried at vacuum condition $\left(50^{\circ} \mathrm{C}\right)$ for $24 \mathrm{~h}$. Nickel oxide nanoparticles were synthesized by a method described as follows: $291 \mathrm{mg} \mathrm{Ni}\left(\mathrm{NO}_{3}\right)_{2} \cdot 6 \mathrm{H}_{2} \mathrm{O}$ was dissolved in $10 \mathrm{~mL}$ water. Then, concentrated ammonia solution was added until formation of $\mathrm{Ni}(\mathrm{OH})_{2}$. The precipitate colour was light green. Addition of ammonia solution was continued just to dissolve $\mathrm{Ni}(\mathrm{OH})_{2}$ and form dark blue nickel-ammonia complex with a solution $\mathrm{pH}$ of $\sim 10$. This solution was then placed near a beaker containing $10 \mathrm{~mL}$ concentrated sulphuric acid in a closed polyethylene container for $48 \mathrm{~h}$ at room temperature. 
A light green powder was precipitated out. The product was washed with distilled water and ethanol and dried at $40^{\circ} \mathrm{C}$ to obtain the nickel oxide nanoparticles [31].

A $2 \mathrm{mg}$ of PANI nanofibers was weighed and doped with $2.5 \mathrm{mg}$ of metal oxides $\mathrm{NiO}$ nanoparticles by mixing the two nanomaterials in $2 \mathrm{~mL}$ DMF. The mixture was stirred for $72 \mathrm{~h}$ at room temperature. The PANI-NiO nanocomposite was dried at $25^{\circ} \mathrm{C}$ for the solvent to evaporate. The obtained $\mathrm{NiO}$ nanomaterials were characterized using spectroscopic and microscopic techniques.

2.4. Electrode Modification Procedure. The GC electrode was polished with $0.3 \mu \mathrm{m}$ and $0.05 \mu \mathrm{m}$ alumina slurries for $3 \mathrm{~min}$, each step followed by thoroughly rinsing with water and sonicating in turn with distilled water, ethanol, and distilled water for $3 \mathrm{~min}$ each before modification. GCE-NiO, GCEPANI, and GCE-PANI-NiO modified electrodes were prepared by a drop-dry method $[32,33]$. Firstly the slurry of the nanoparticles was prepared by dissolving $2 \mathrm{mg}$ each of $\mathrm{NiO}$ and PANI separately in $1 \mathrm{~mL}$ DMF. Slurry of PANI$\mathrm{NiO}$ nanocomposites was prepared by mixing $2 \mathrm{mg}$ PANI and $2.5 \mathrm{mg} \mathrm{NiO}$ in $1 \mathrm{~mL}$ DMF. About $20 \mu \mathrm{L}$ of slurry was dropped on the bare GCE and dried in an oven at $50^{\circ} \mathrm{C}$ for about 2 min to give GCE-NiO, GCE-PANI, and GCE-PANI-NiO electrodes. Successful modification of the GCE electrode with the nanomaterials and their nanocomposites was confirmed by running the cyclic voltammetry $(\mathrm{CV})$ of each developed sensor in $1 \mathrm{M} \mathrm{HCl}$ and $1 \mathrm{M} \mathrm{H}_{2} \mathrm{SO}_{4}$ in the potential window of $-0.2 \mathrm{~V}$ to $1.4 \mathrm{~V}$ (scan rate, $25 \mathrm{mV} / \mathrm{s}$ ).

\section{Results and Discussion}

\subsection{Spectroscopic and Microscopic Characterization}

3.1.1. UV-Vis Spectroscopy Result. UV-Vis absorption spectroscopic analyses were performed to confirm the formation of the PANI-NiO nanocomposites. UV-Vis absorption spectra for $\mathrm{NiO}$ (Figure 1) showed a strong absorption peak at $340 \mathrm{~nm}$ which is a characteristics peak for nickel oxide nanoparticles [34]. The PANI-NiO nanocomposites showed two strong absorption peaks at approximately 348 and $622 \mathrm{~nm}$, respectively. The absorption peak at $348 \mathrm{~nm}$ indicates a slight shift in the $\mathrm{NiO}$ absorption band at $340 \mathrm{~nm}$ suggesting the chemical interaction of the $\mathrm{NiO}$ with the PANI nanofibers molecules. This shift might be due to the benzenoid $\pi-\pi^{*}$ transition of the PANI nanofibers in the PANI-NiO nanocomposites. Secondly, the reduction in the $\mathrm{NiO}$ peak intensity and the increase in the PANI peak intensity at $608 \mathrm{~nm}$ confirm successful synthesis of the PANI-NiO nanocomposites. This peak at $622 \mathrm{~nm}$ has been attributed to $\pi-\pi^{*}$ transition of quinine-imines group attributed to the formation of emeraldine base. This result is similar to previously reported results for polyaniline powders, thin films, nanotubes, and nanofibers $[30,35]$. The fact that there was no shift in the wavelength of PANI at $458 \mathrm{~nm}$ in the nanocomposites PANI-NiO suggests that the chemical structure of PANI was not altered in the nanocomposites preparation.

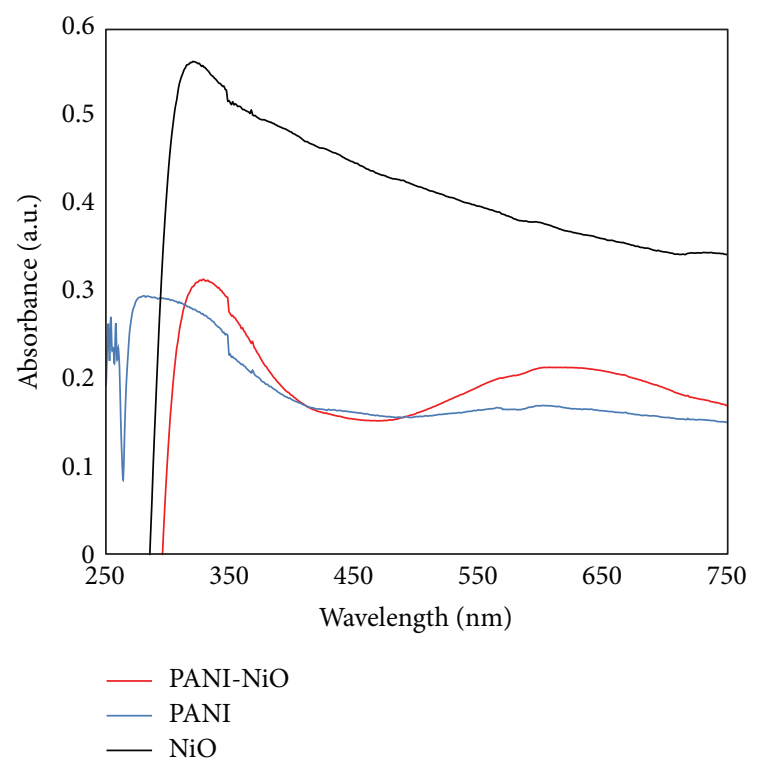

FIgURE 1: UV-Vis spectra of $\mathrm{NiO}$ nanoparticles, PANI nanofibers, and PANI-NiO nanocomposites.

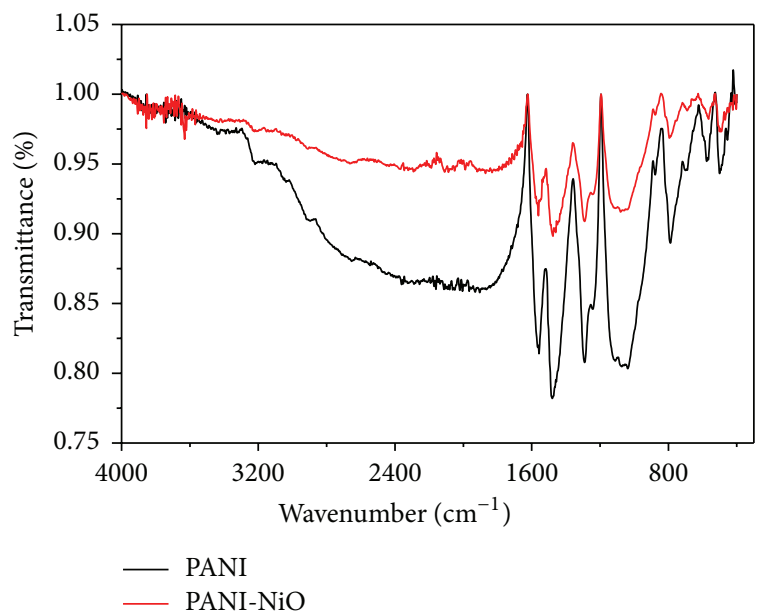

FIGURE 2: FTIR spectra of PANI nanofiber and PANI-NiO nanocomposite.

3.1.2. FTIR. Figure 2 shows the FTIR spectra of PANI and PANI-NiO nanocomposites. The spectra of PANI show the main characteristic peaks at 1580,1500, 1287, 1147, and $824 \mathrm{~cm}^{-1}$. The bands at 1580 and $1500 \mathrm{~cm}^{-1}$ are attributed to stretching vibrations of $\mathrm{N}=\mathrm{N}$ ring and $\mathrm{N}-\mathrm{N}$ ring for benzenic rings and quinonic rings, respectively, while the bands at $1287 \mathrm{~cm}^{-1}$ correspond to $\mathrm{NH}$ bending, and $1147 \mathrm{~cm}^{-1}$ was assigned to $\mathrm{C}-\mathrm{N}$ stretching of secondary aromatic amine [36]. The out-of-plane bending vibration of $\mathrm{C}-\mathrm{H}$ on the 1,4-disubstituted aromatic rings was assigned to the peak at $824 \mathrm{~cm}^{-1}$ [30]. The reduction in the intensity of these PANI characteristic peaks in PANI-NiO and the reduction in PANI broad band intensity at around $2400 \mathrm{~cm}^{-1}$ indicate successful transformation of the PANI molecule to PANI$\mathrm{NiO}$ nanocomposites. 


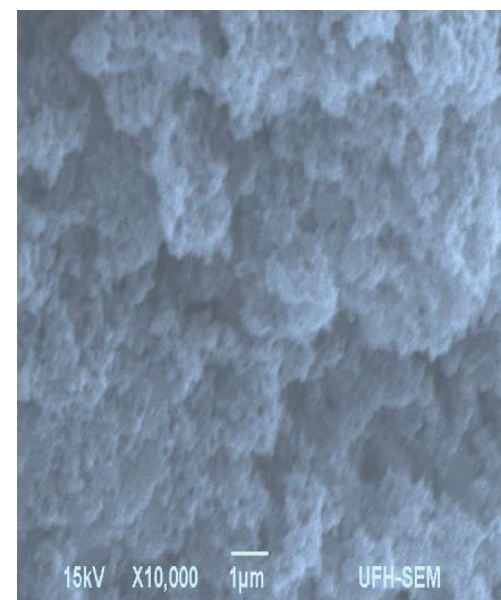

(a)

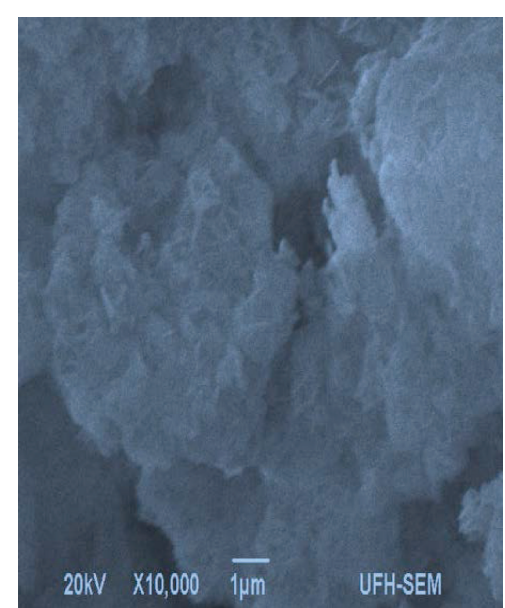

(b)

FIgURE 3: SEM images of (a) PANI nanofibers and (b) PANI-NiO nanocomposites.

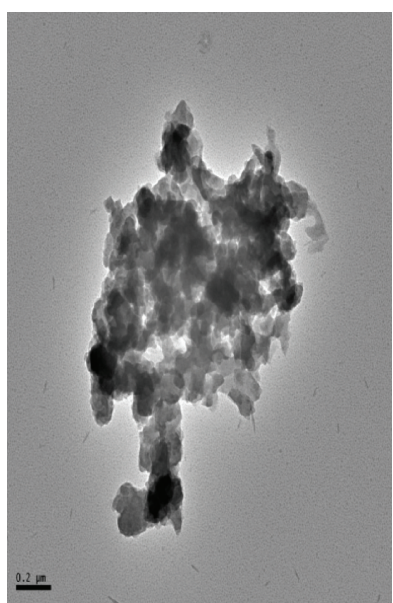

(a)

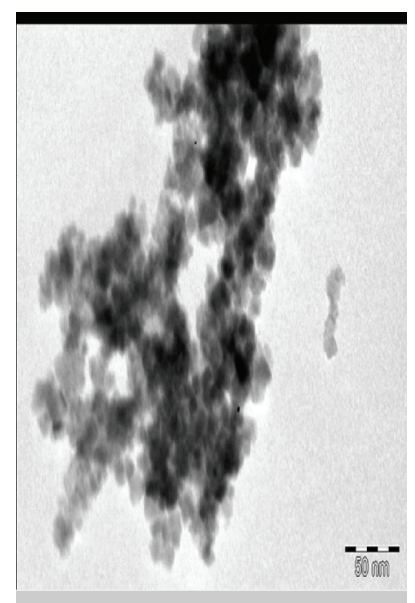

(b)

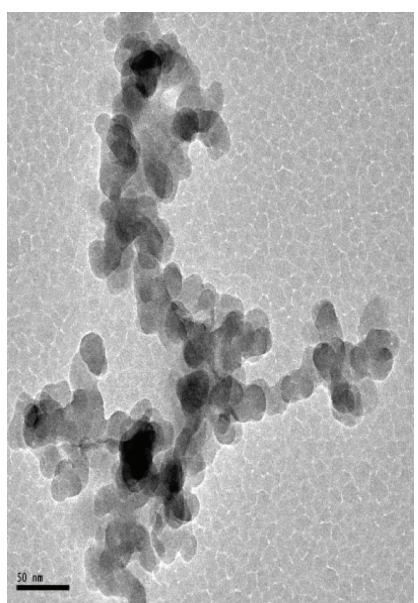

(c)

FIgURE 4: TEM images of (a) PANI nanofibers, (b) NiO nanoparticle, and (c) PANI-NiO nanocomposites.

\subsection{SEM, TEM, EDX, and XRD of PANI and PANI-NiO Nanocomposites}

3.2.1. SEM. The SEM images of the PANI nanofibers and PANI-NiO nanocomposites are shown in Figure 3. Figure 3(a) showed that the PANI nanofiber has larger surface area due to its porous morphology, while the PANI-NiO (Figure 3(b)) forms aggregate porous layers with flower-like $\mathrm{NiO}$ nanoparticles dispersed and embedded in the nanofibers. The successful formation of the PANI$\mathrm{NiO}$ nanocomposites can be attributed to ionic interaction between the two nanomaterials. Similar reports on the successful formation of metal oxide/carbon nanomaterial based nanocomposites have been attributed to either $\pi-\pi$ or electrovalent interaction between the metal oxide and the carbon based nanomaterial [37].

3.2.2. TEM. The TEM images of PANI, NiO nanoparticles, and PANI/NiO nanocomposites are shown in Figure 4.
The morphology of PANI nanofibers (Figure 4(a)) shows small, spherical but closely packed particles probably due to $\pi-\pi$ interactions between the PANI molecules. The estimated length of the PANI nanofibers was approximately $85 \mathrm{~nm}$. NiO nanoparticles (Figure 4(b)) were mostly spherical with approximate diameter of about $40 \mathrm{~nm}$. The nanocomposites formed after doping $\mathrm{NiO}$ into PANI nanofibers (PANI/NiO) (Figure 4(c)) exhibited close shape with that of $\mathrm{NiO}$ nanoparticles and showed some form of aggregation probably due to $\pi-\pi$ and electrovalent interaction between the metal oxide and PANI molecules $[37,38]$.

3.2.3. EDX. The EDX spectrum of the PANI-NiO nanocomposites is presented in Figure 5. The prominence of the nickel $(\mathrm{Ni}=46.67 \%)$ and oxygen $(\mathrm{O}=36.88 \%)$ peaks confirmed the presence of $\mathrm{NiO}$ nanoparticles in the PANI-NiO. Similarly, the presence of nitrogen $(\mathrm{N}=7.94 \%)$ and carbon $(\mathrm{C}=6.47 \%)$ peaks though with lower peak intensity further reveals the 


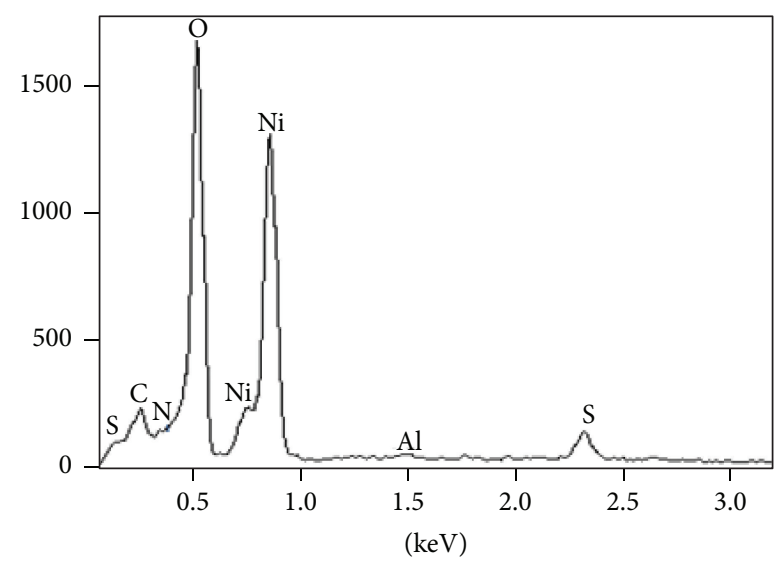

FIgURE 5: EDX spectra of PANI-NiO nanocomposites.

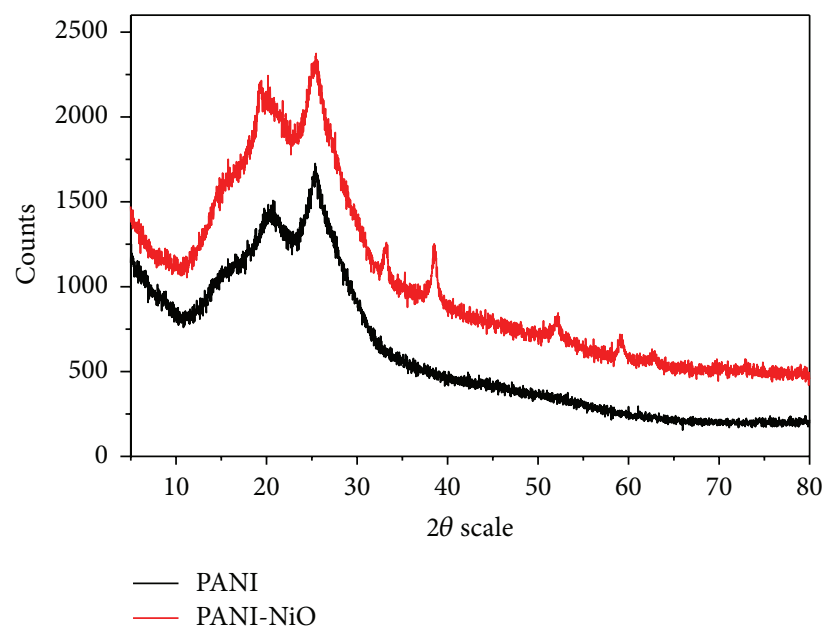

FIGURE 6: XRD spectra of $\mathrm{NiO}$ nanoparticles and PANI-NiO nanocomposite.

presence of PANI molecules and the successful preparation of the PANI-NiO nanocomposites.

3.2.4. XRD. The XRD spectra of PANI and PANI/NiO are shown in Figure 6. For PANI, the characteristics peaks at $2 \theta=200$ and 260 correspond to $(020)$ and (200) crystal planes of PANI [39]. After the incorporation of $\mathrm{NiO}$ into the PANI matrix to form PANI-NiO composite, characteristics peaks that appear at $2 \theta=330,380$, and 610 , respectively, corresponding to (111), (200), and (220) indices confirming the presence of $\mathrm{NiO}$ nanoparticles well dispersed in the PANI polymer matrix as observed from the SEM images. The result further confirms the formation of the PANI-NiO nanocomposites. Using Debye-Scherrer formula [40],

$$
d=\frac{K \lambda}{B \cos \theta},
$$

where $d$ is the average crystal size; $K$ is a constant (0.89); $\lambda$ is the wavelength $(1.78901 \mathrm{~nm})$ used; $B$ is the full width at half maximum of the peak, $\theta$ is Bragg's angle of the XRD peak, and the crystal sizes of the $\mathrm{NiO}$ nanoparticles were estimated from three prominent peaks to be $\sim 50 \mathrm{~nm}$ which falls in the range reported for the TEM above.

3.3. Electrochemical Characterization of Modified Electrodes. Figure 7 is the cyclic voltammograms of polyaniline nanofibers on glassy carbon electrode (GCE-PANI) in $1 \mathrm{M} \mathrm{H}_{2} \mathrm{SO}_{4}$ solution at a scan rate of $25 \mathrm{mVs}^{-1}$. The main complication in understanding the anodic protection mechanism of PANI is the fact about its different possible equilibrium states as shown in Figure 7(b). Thus in this electrolyte, three redox peaks AA1, BB1, and $\mathrm{CC} 1$ at $(0.2 / 0.12 \mathrm{~V}),(0.4 / 0.32 \mathrm{~V})$, and $(0.52 / 0.42 \mathrm{~V})$ oxidation/reduction potentials, respectively, were observed. The oxidation state increases from completely reduced leucoemeraldine to emeraldine and to the fully oxidized form pernigraniline. However not all the possible PANI states are conductive; actually PANI emeraldine form is the only conductive form [19]. The first redox peak $\mathrm{AA}^{\prime}$ is due to the conversion of leucoemeraldine to emeraldine salt while the third redox peak $\mathrm{CC}^{\prime}$ is due to the conversion of emeraldine salt to pernigraniline form. The redox couple $\mathrm{BB}^{\prime}$ at the centre is due to impurities such as the benzoquinone and the hydroquinone in the polyaniline [30,41, 42].

The current density increases with the number of cycles which indicates the transition of emeraldine to pernigraniline form as well as the uniform growth of the PANI layer [30, 43]. The variation of Ip with $\nu^{1 / 2}$ was carried out for the first oxidation peak to ensure the reversibility of the polymer. The peak current (Ip) depends linearly on the square root of scan rate $\left(v^{1 / 2}\right)$ (not shown) indicating the diffusion-controlled process.

A comparative cyclic voltammetry study was also performed on the modified electrodes GCE, GCE/PANI, and $\mathrm{GCE} / \mathrm{PANI}-\mathrm{NiO}$ in $1 \mathrm{M} \mathrm{HCl}$ at scan rate, $20 \mathrm{mVs}^{-1}$. The CV curve shows two sets of distinct redox activities for all the electrodes as indicated by the two pairs of anodic and cathodic current peaks (Figure 8(a)). The first redox couple which appears between 0 and $0.15 \mathrm{~V}$ (versus $\mathrm{Ag} / \mathrm{AgCl}$ ) is associated with the conversion of the fully reduced leucoemeraldine base to the partially oxidized emeraldine, and the second couple occurring between 0.56 and $0.60 \mathrm{~V}$ versus $\mathrm{Ag} / \mathrm{AgCl}$ indicate the conversion of emeraldine to the fully oxidized pernigraniline form [30, 41, 42]. From the overlaid cyclic voltammetry shown in Figure 8(a), it is obvious that the GCE/PANI-NiO have a higher current response than the other electrodes. The results indicate that the modification of the PANI-NiO nanocomposites onto the GC electrode surface increases the peak current in $1 \mathrm{M} \mathrm{HCl}\left(I_{\mathrm{pa}}: 59.8 \mu \mathrm{A}\right)$ compared to GCE-PANI $\left(I_{\mathrm{pa}}: 17.8 \mu \mathrm{A}\right)$ and the unmodified GC electrode $\left(I_{\mathrm{pa}}: 0.43 \mu \mathrm{A}\right)$. This could be attributed to the aggregated layers of the PANI nanofibers with high surface area and good electrical conductivity which facilitate faster and more electron transport between the electrolyte and the base GC electrode. The embedded conducting $\mathrm{NiO}$ nanoparticles also form a synergy with the PANI nanofibers forming PANI-NiO nanocomposites with newer functionalities and enhanced electron transport behaviour than PANI or GC electrode alone. Similar results have been reported 


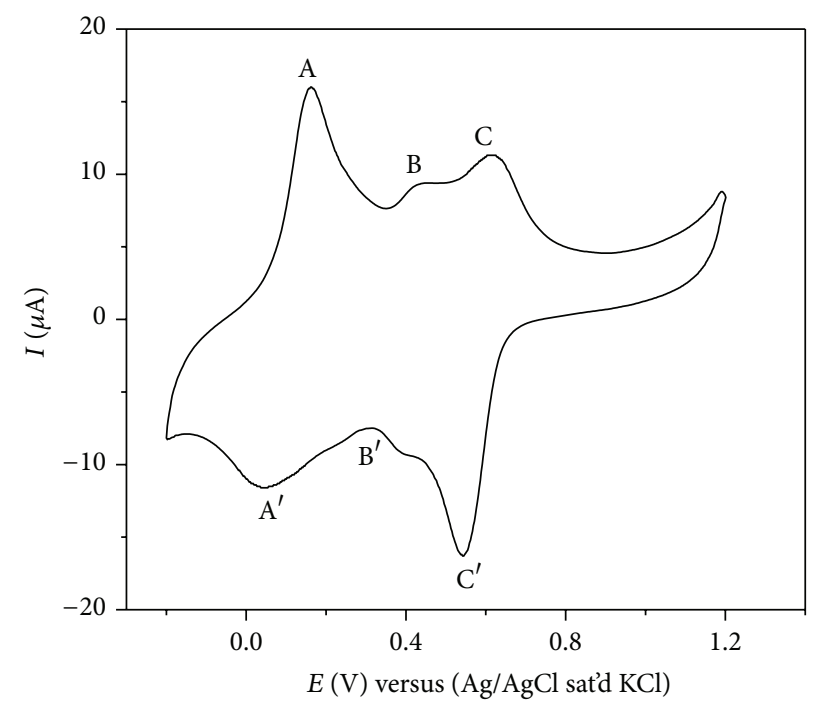

(a)<smiles>CNc1ccc(Nc2ccc(Nc3ccc(Nc4ccc(C)cc4)cc3)cc2)cc1</smiles>

Leucoemeraldine form<smiles>CN=C1C=CC(=Nc2ccc(N=C3C=CC(=Nc4ccc(C)cc4)C=C3)cc2)C1</smiles>

Pernigraniline form

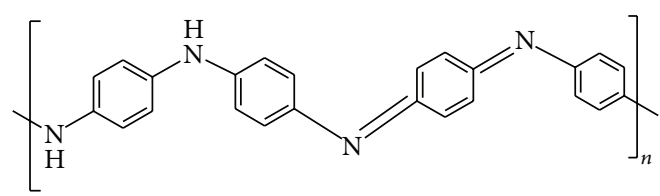

Emeraldine base, intermediate form

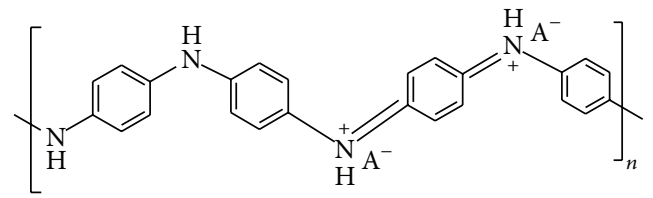

Emeraldine salt, conducting form

(b)

Figure 7: (a) Cyclic voltammogram of GCE-PANI nanofibers modified electrode in $1 \mathrm{M} \mathrm{H}_{2} \mathrm{SO}_{4}$ at a scan rate of $25 \mathrm{mVs}{ }^{-1}$. (b) Different possible equilibrium states of PANI.

for modified electrodes in literature [30, 41, 42]. Therefore to further investigate the kinetics of electrode reactions, cyclic voltammograms at different scan rates were obtained for the modified GCE-PANI-NiO electrode and results are discussed in Section 3.5.

3.4. Electrochemical Impedance Spectroscopy Study. Electrochemical impedance spectroscopy has been an important technique in investigating the complex electrochemical process taking place on the surface of an electrode or charge transfer process at the electrode/electrolyte interface. It is known to be an effective method of probing the extent of electron transport properties of the modified electrodes. Electrochemical impedance was used to investigate the charge transport process of the GCE, GCE/PANI, and GCE/PANI$\mathrm{NiO}$ electrodes in $1 \mathrm{M} \mathrm{HCl}$ electrolyte and this was done by monitoring charge transfer resistance $\left(R_{\mathrm{ct}}\right)$ at the electrode/electrolyte interface. The measurement was done in $1 \mathrm{M} \mathrm{HCl}$ solution (at fixed potential of $0.2 \mathrm{~V}$ versus $\mathrm{Ag} / \mathrm{AgCl}$, sat'd $\mathrm{KCl}$ ) within a frequency range of $10 \mathrm{KHz}$ to $0.1 \mathrm{~Hz}$. The
Nyquist plots obtained for the electrodes are presented in Figure $8(\mathrm{~b})$. The impedance data were fitted with an electrical circuit model represented as inset in Figure 8(b) where $R_{s}$ is the solution resistance, $C_{\mathrm{dl}}$ is the double layer capacitance, $R_{\text {ct }}$ is the charge transfer resistance, and $Q$ is the constant phase element. The circuit $R C([R Q])$ (i) was used for PANI and PANI-NiO, while $R(C[R Q])$ (ii) was used for the bare GCE electrode. It is important to mention at this juncture that the two circuits look very similar except that, in circuit (i), the solution resistance $R_{s}$ is not in series to $C_{\mathrm{dl}}$ while in circuit (ii) it is directly in series. This slight change in circuit configuration is in response to changes in the electronic configuration of the GCE-PANI and GCE-PANI$\mathrm{NiO}$ modified electrodes with newer functionalities and enhanced electron transport behaviour as compared to GC electrode alone. All the obtained spectra were first subjected to the Kramers-Kronig (K-K) test $[44,45]$. Failure of the K$\mathrm{K}$ test signified by a large value of pseudo $\chi^{2}$ is usually an indication that no good fit can be obtained using the electrical equivalent circuit's methods. It should be noted that aside 


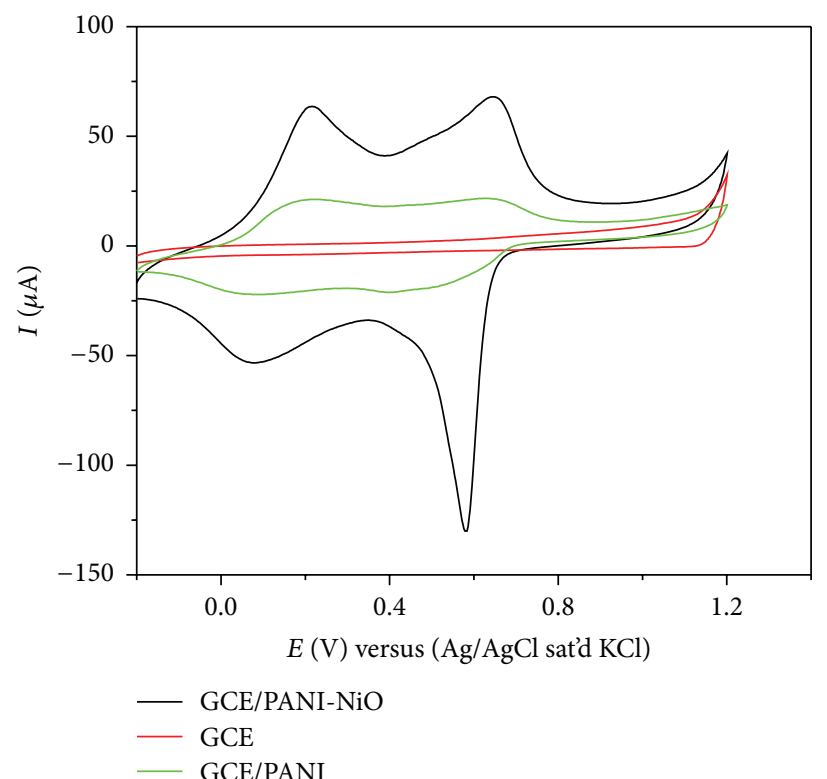

(a)

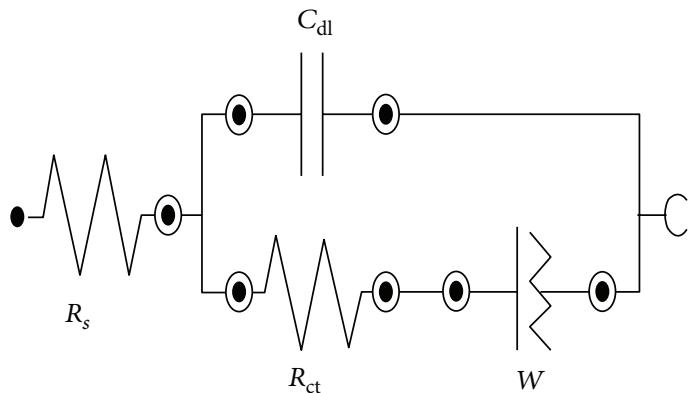

(bi)

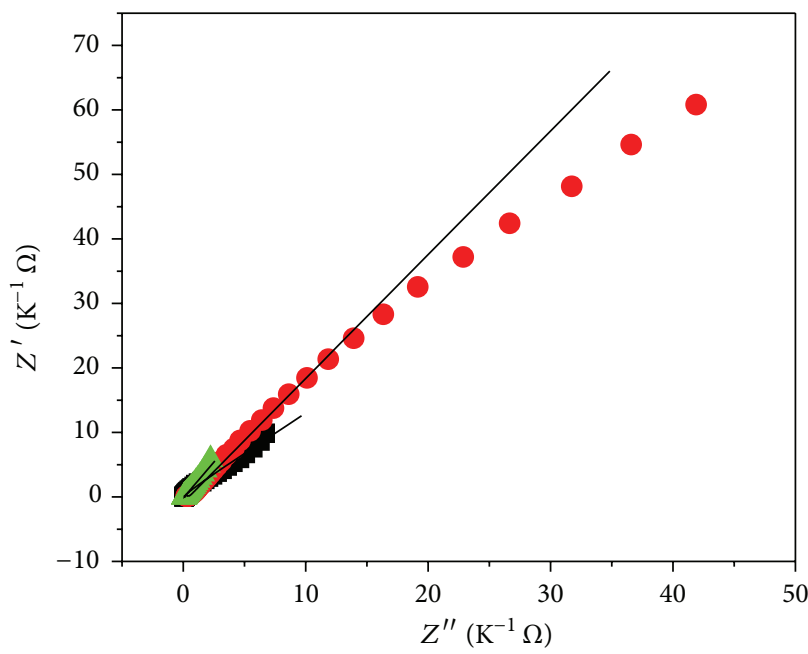

GCE/PANI

GCE

GCE/PANI-NiO (b)

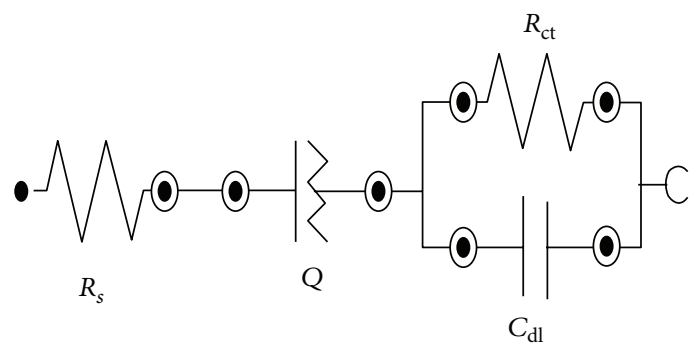

(bii)

Figure 8: (a) Comparative cyclic voltammograms for GCE, GCE/PANI, and GCE/PANI-NiO in $1 \mathrm{M} \mathrm{HCl}$ at scan rate, $20 \mathrm{mVs}^{-1}$. (b) Nyquist plot of the EIS measurement for GCE, GCE/PANI, and GCE/PANI-NiO in $1 \mathrm{M} \mathrm{HCl}$. (bi) Randle's equivalent circuit used for fitting the Nyquist plots for GCE and (bii) Randle's equivalent circuit used for fitting the Nyquist plots GCE/PANI and GCE/PANI-NiO, respectively.

TABLE 1: Charge transfer resistance $\left(R_{\mathrm{ct}}\right)$, double layer capacitance $\left(C_{\mathrm{dl}}\right)$, and exchange current $\left(i_{0}\right)$ for various electrodes in $1 \mathrm{M} \mathrm{HCl}$ solution.

\begin{tabular}{lccc}
\hline Electrodes & $R_{\mathrm{ct}}(\Omega)$ & $C_{\mathrm{dl}}(\mu \mathrm{F})$ & $i_{0}(\mathrm{~A})$ \\
\hline GCE & 147.4 & 5.25 & $1.742 \times 10^{-4}$ \\
GCE/PANI & 212.7 & 0.14 & $1.207 \times 10^{-4}$ \\
GCE/PANI-NiO & 40.2 & 0.32 & $6.386 \times 10^{-4}$ \\
\hline
\end{tabular}

from visual inspection of goodness of the fitting lines two accurate ways to establish how well the modelling functions reproduce the experimental data sets are the relative error estimates (in \%) and chi-square functions $\left(\chi^{2}\right)$ [46], which is the sum of squares of the relative residuals (i.e., sum of the real and imaginary $\chi^{2}$ ), easily obtained from the K-K test.

The charge transfer resistance $\left(R_{\mathrm{ct}}\right)$ values calculated after fitting the EIS data to Randle's equivalent circuit in Table 1 confirm that $\mathrm{NiO}$ nanoparticles decreased the resistance of PANI by $172.5 \Omega$ suggesting the suitability of GCE-PANI$\mathrm{NiO}$ as a good conducting platform for electrocatalysis. This behaviour may be due to the synergy between the highly conducting nickel oxide nanoparticle and the porous conducting PANI nanofibers with large surface, thus facilitating more charge flow (at lower transfer resistance) between the electrolyte and the GC electrode. The result is further supported by the higher current response recorded at GCE-PANI-NiO electrode from the CV experiment. This result also agreed with other reports in literatures for enhanced electrochemical responses of chemically modified electrodes compared with unmodified electrodes [29, 47]. The exchange current can be thought of as a background current to which the net current observed at various over potentials is normalized. The exchange current was calculated using (2) [39] as follows:

$$
i_{0}=\frac{R T}{n F R_{\mathrm{ct}}},
$$

where $i_{0}$ is the exchange current, $R$ is the gas constant, that is, $8.314 \mathrm{~J} \mathrm{~mol}^{-1} \mathrm{~K}^{-1}, T$ is the absolute temperature $(\mathrm{K}), n$ is the number of moles of electron transfer, $F$ is the Faraday constant, and $R_{\mathrm{ct}}$ is the electron charge transfer. The highest 


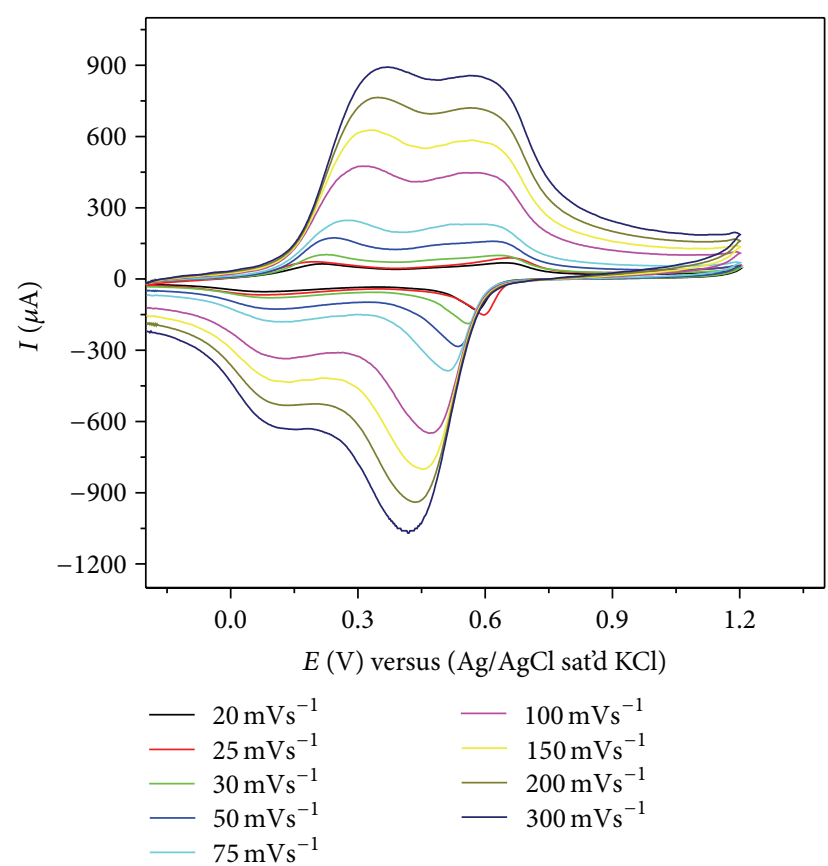

(a)

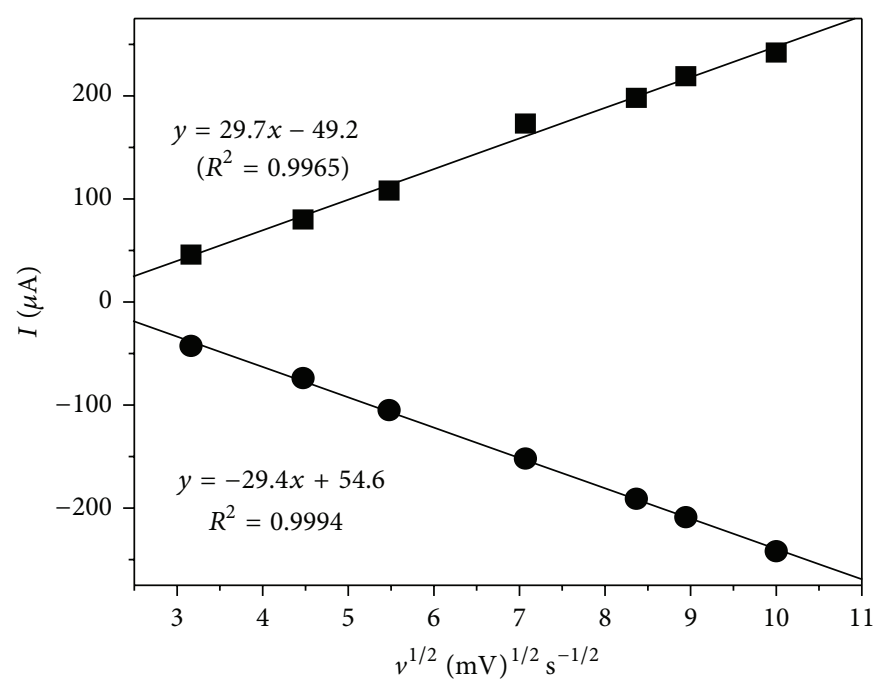

(b)

Figure 9: (a) Cyclic voltammograms of GCE/PANI-NiO electrode in $1 \mathrm{M} \mathrm{HCl} \mathrm{solution} \mathrm{(scan} \mathrm{rate} \mathrm{range} \mathrm{20-300} \mathrm{mVs}^{-1}$ ) and (b) linear plots of $I_{\mathrm{pa}}$ versus $\nu^{1 / 2}$ and $I_{\mathrm{pc}}$ versus $\nu^{1 / 2}$ for GCE/PANI-NiO electrode in $1 \mathrm{M} \mathrm{HCl}$ solution.

value of exchange current $i_{0}$ for GCE-PANI-NiO electrode as shown in Table 1 suggests that the electrochemical activity of the PANI-NiO is superior compared to that of other electrodes studied.

3.5. Effect of Scan Rate. The effect of scan rate (scan rate ranging from 20 to $300 \mathrm{mVs}^{-1}$ ) on the current response of PANI-NiO modified glassy carbon electrode (GCE-PANI$\mathrm{NiO}$ ) was investigated in $1 \mathrm{M} \mathrm{HCl}$ (Figure 9). Result showed there is an increase in anodic peak current as the scan rate increases (Figure 9(a)). Therefore the plot of the anodic $\left(I_{\mathrm{pa}}\right)$ and cathodic $\left(I_{\mathrm{pc}}\right)$ peak currents versus square root of scan rate $\left(\nu^{1 / 2}\right)$ gave a linear relationship (Figure $9(\mathrm{~b})$ ) with the regression equations as presented below:

$$
\begin{array}{r}
I_{\mathrm{pa}}=2.97 \times 10^{-6}-4.92 \times 10^{-6} \times v^{1 / 2}\left(\mathrm{mVs}^{-1}\right)^{1 / 2} \\
\left(R^{2}=0.9965\right), \\
I_{\mathrm{pc}}=-2.94 \times 10^{-5}+5.46 \times 10^{-5} \times v^{1 / 2}\left(\mathrm{mVs}^{-1}\right)^{1 / 2} \\
\\
\left(R^{2}=0.9994\right) .
\end{array}
$$

The result suggests a diffusion controlled electrode reaction $[19,41]$. In addition, with increasing scan rate, the peak potential $E(p)$ shifts to more positive values and there is a linear correlation between the peak potential and the $\operatorname{logarithm}$ of scan rate $(\log v)$ (graph not shown). In order to get information on the rate determining step, the peak potential, $E(p)$, is plotted against $\log \nu$ (graph not shown). The slope of $E(p)$ versus $\log v$ for the modified electrode
GCE-PANI-NiO is $0.0279 \mathrm{~V}$. From the slope obtained, the Tafel value (b) may be estimated according to (4) for totally irreversible diffusion controlled process [48]. So, the value of $b$ for this electrode was obtained as $55.8 \mathrm{mVdec}^{-1}$ :

$$
E(p)=\left(\frac{b}{2}\right) \log \nu+\text { constant. }
$$

The Tafel value falls within the range of normal values $(\sim 30-$ $120 \mathrm{mV} / \mathrm{dec}$ ) for a single-electron process involved in the rate determining step. This value indicates that a fast electron transfer is followed by a slow chemical step [49].

3.6. Electrochemical Response of the Electrodes to Phenanthrene Oxidation. The polyaniline nanocomposites were developed to enhance the catalytic activity of the nanoparticles for the detection of phenanthrene. The electrochemical behaviour of different modified electrodes in the presence of $3 \times 10^{-6} \mathrm{M}$ phenanthrene in $1 \mathrm{M} \mathrm{HCl}$ was investigated by cyclic voltammetric (CV) technique at a scan rate of $20 \mathrm{mV} / \mathrm{s}$. Figure 10 shows the $\mathrm{CV}$ responses obtained for the bare GCE, GCE/PANI, and GCE/PANI-NiO electrodes in the presence of $3 \times 10^{-6} \mathrm{M}$ phenanthrene. At a bare GCE, GCE/PANI, and GCE/PANI-NiO, a well-defined anodic peak was observed at $1540 \mathrm{mV}, 1550 \mathrm{mV}$, and $1650 \mathrm{mV}$, respectively, corresponding to phenanthrene oxidation peak potential. This oxidation potential agreed closely with phenanthrene oxidation potential reported for some chemically modified electrodes $[19,50]$. Among the three electrodes, GCE/PANI$\mathrm{NiO}$ gave the best current response $(750 \mu \mathrm{A})$ compared to the other electrodes, GCE/PANI $(680 \mu \mathrm{A})$ and bare GCE $(390 \mu \mathrm{A})$. The current response at GCE/PANI-NiO electrode 


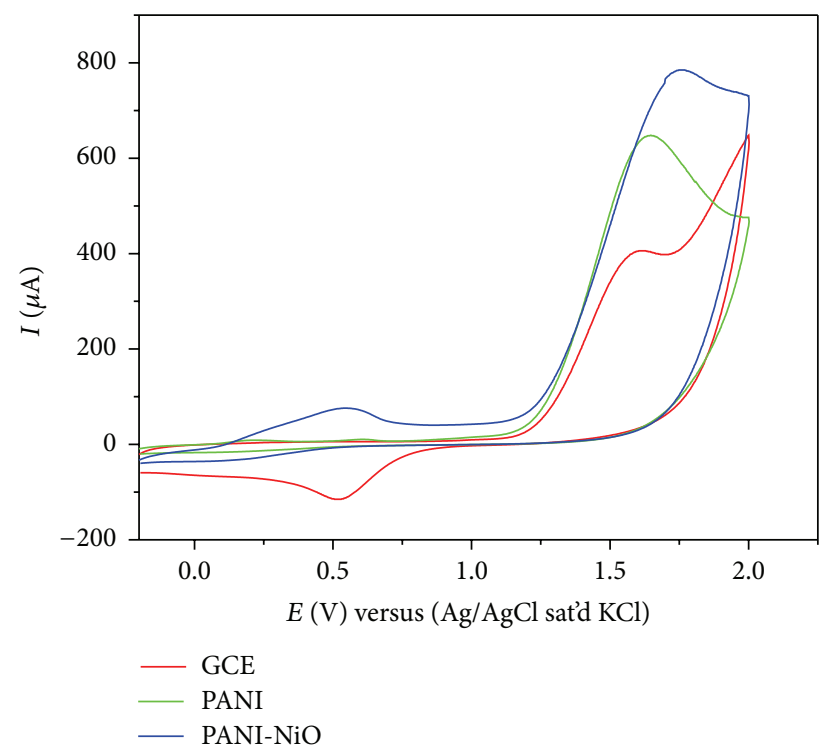

Figure 10: Cyclic voltammograms of GCE, GCE/PANI, and $\mathrm{GCE} / \mathrm{PANI}-\mathrm{NiO}$ in $3 \times 10^{-6} \mathrm{M}$ phenanthrene in $1 \mathrm{M} \mathrm{HCl}$ at scan rate $20 \mathrm{mVs}^{-1}$.

towards phenanthrene was $\sim 8$ times higher than at the bare GCE. This is attributed to the synergy in PANI-NiO leading to the improved electrocatalytic properties of the surface nanocomposites material [51]. The lower phenanthrene oxidation potential on this electrode suggests large surface area created by the porous PANI material allowing easy contact between the analyte and the $\mathrm{NiO}$ catalyst, thus faster reaction kinetics at lower energy. These results indicate that the GCE/PANI-NiO has high electrocatalytic activity towards the oxidation of phenanthrene. It is believed that the existence of $\mathrm{NiO}$ nanoparticles in the PANI nanofibers plays an important role in the electron transfer between the surface electroactive catalyst and the base GC electrode after phenanthrene oxidation. The result obtained in this study agreed with similar observation for phenanthrene oxidation on graphenated polyaniline-doped tungsten oxide nanocomposites on glassy carbon electrode which was reported to be better compared to the bare GCE and other developed sensors signifying the importance of chemically modified electrodes in catalysis [19]. Since GCE/PANI-NiO electrode demonstrated excellent catalytic properties towards phenanthrene oxidation in this study, further studies were carried out using this electrode unless otherwise stated.

3.6.1. Effect of Scan Rate. The effect of scan rate (scan rate, $10-300 \mathrm{mVs}^{-1}$ ) on the response of $3 \times 10^{-6} \mathrm{M}$ phenanthrene at PANI-NiO modified glassy carbon electrode was investigated in $1 \mathrm{M} \mathrm{HCl}$ (Figure 11(a)). Result showed that there is an increase in anodic peak current as the scan rate increases. The plot of the anodic peak current of phenanthrene against square root of scan rate $\left(\nu^{1 / 2}\right)$ over the scan range study showed a linear relationship (Figure 11(b)) with a linear regression equation $I_{\mathrm{pa}}=3.15 \times 10^{-6}-6.08 v^{1 / 2}\left(R^{2}=\right.$ $0.9985)$. This indicated that electrochemistry of the process was limited by rate of diffusion of phenanthrene from the solution to the surface of the electrode. It was also observed that the oxidation peak potential was shifting to more positive potentials which further confirms that the electrode process was diffusion-controlled [41]. This indicated that the surface electrochemistry was limited by diffusion of solution of electrolyte/analyte to the surface of the electrode [43].

The slope of $E(p)$ versus $\log v$ for the modified electrode GCE-PANI-NiO is $0.1135 \mathrm{~V}$. The Tafel slopes $(b)$ may be estimated according to (2) for totally irreversible diffusion controlled process. So, the value of $b$ for this electrode was obtained as $227 \mathrm{mVdec}^{-1}$. This Tafel value is higher than the theoretical value of $118 \mathrm{mVdec}^{-1}$ for a one-electron process involved in the rate-determining step. Therefore higher Tafel values are attributed to the adsorption of reactants or intermediates on the electrode surfaces. These also indicate that the electrode surface is porous and despite this fact the modified electrodes still gave better performance towards phenanthrene in terms of oxidation potential, current recovery, stability, and resistance to fouling effects.

3.7. Electroanalysis of Phenanthrene. A concentration study was carried out using square wave voltammetric (SWV) method. Result indicates that the electrochemical response of phenanthrene at GCE/PANI-NiO modified electrode gave phenanthrene oxidation peak current that is linearly proportional to its concentration in the range $7.6 \mathrm{pM}-1.4 \times$ $10^{-11} \mathrm{M}$ (Figure 12). The detection limit was calculated based on the relationship LoD $=3.3 \delta / \mathrm{m}[52]$ where $\delta$ is the relative standard deviation of the intercept of the $y$-coordinates from the line of best fit, and $m$ is the slope of the same line. The limits of detection and sensitivity of the GCE/PANI-NiO electrode in phenanthrene are $0.732 \mathrm{pM}$ and $1.04 \times 10^{6} \mathrm{~A} / \mathrm{M}$, respectively. The $0.732 \mathrm{pM}$ reported for phenanthrene agreed closely with $5.0 \times 10^{-13} \mathrm{M}$ recently reported [52] but of higher magnitude lower compared with $19 \mathrm{nM}$ reported on dendritic 7T-Polythiophene modified electrode [51].

3.8. Stability, Reproducibility, and Interference Studies. Reproducibility of the PANI-NiO modified electrode was investigated towards the phenanthrene oxidation in the presence of $3 \times 10^{-6} \mathrm{M}$ phenanthrene in $1 \mathrm{M} \mathrm{HCl}$ solution. $\mathrm{CV}$ analysis was repeatedly performed (20 scans) and monitored in a solution of $1 \mathrm{M} \mathrm{HCl}$ containing $3 \times 10^{-6} \mathrm{M}$ phenanthrene. The phenanthrene oxidation current was stable with less than $10 \%$ drop in the peak current between the 1st and 20th scan as shown in Figure 13. Thus, the GCE/PANI-NiO electrode has demonstrated good stability to electrode fouling effect during phenanthrene oxidation. However, on rinsing the electrodes in a fresh PBS ( $\mathrm{pH}$ 7.0) solution, the electrode surface was renewed and more than $90 \%$ of the initial catalytic current was obtained, indicating the electrochemical stability and reusability of the electrode after analysis. Similarly, after storage for four weeks in a refrigerator, no significant change in serotonin current was observed which confirmed the electrode stability towards the analyte. Interference study was also carried out with the modified electrode in the presence of inorganic ions such as $\mathrm{Cl}^{-}, \mathrm{SO}_{4}{ }^{2-}$, and $\mathrm{NO}^{3-}$ which 


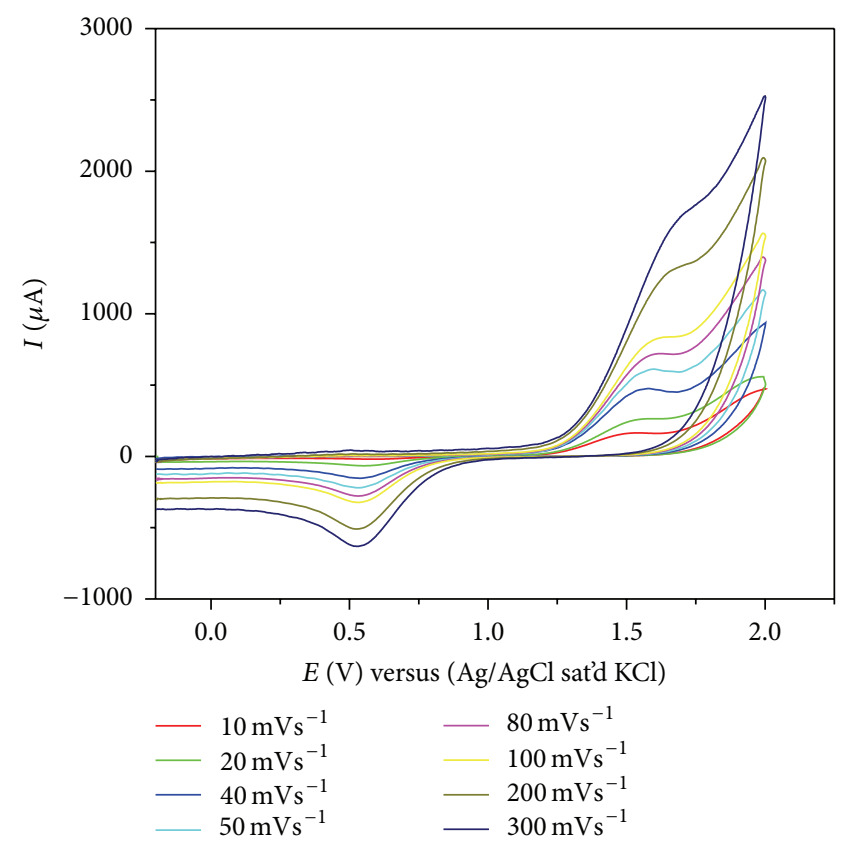

(a)

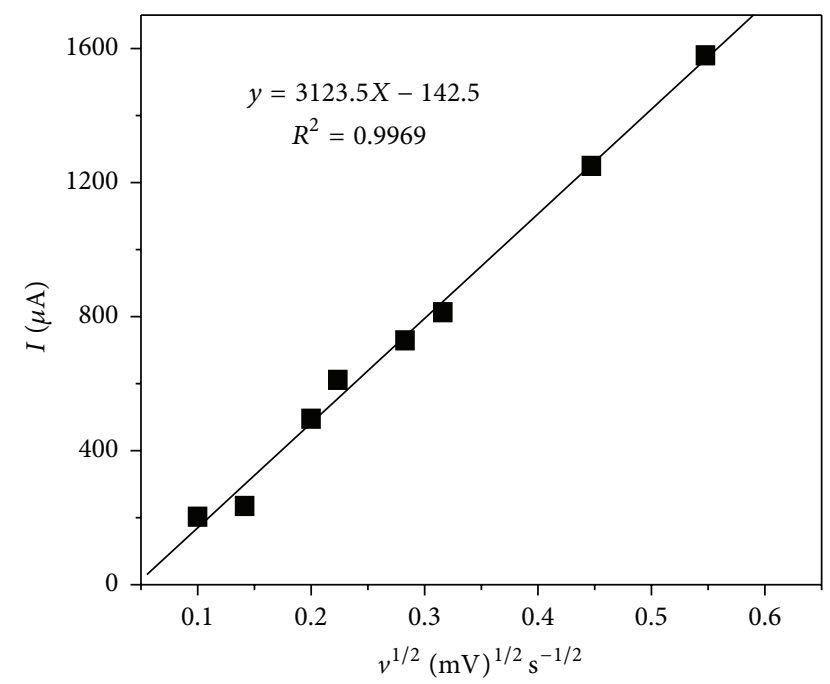

(b)

FIGURE 11: (a) Scan rate dependence cyclic voltammograms of GCE/PANI-NiO sensor in $1 \mathrm{M} \mathrm{HCl} \mathrm{containing} 3 \times 10^{-6} \mathrm{M}$ phenanthrene, (b) linear plot of the anodic peak currents against square root of scan rate.

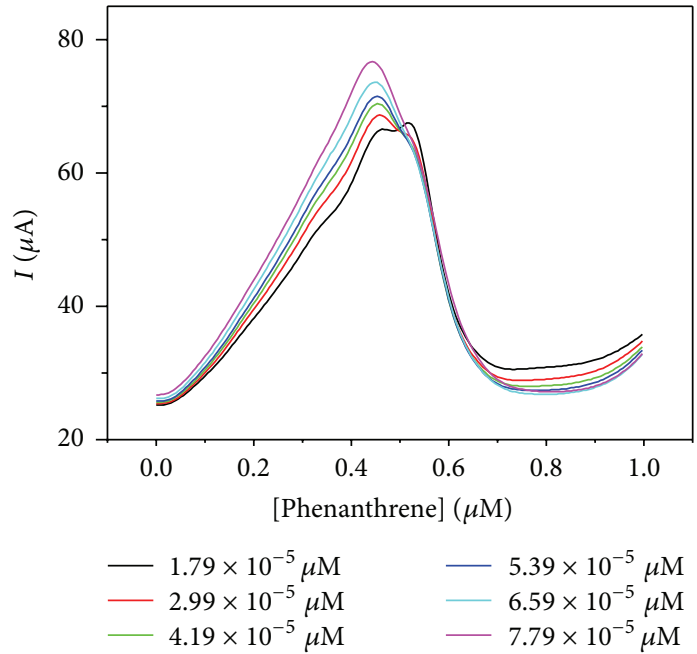

(a)

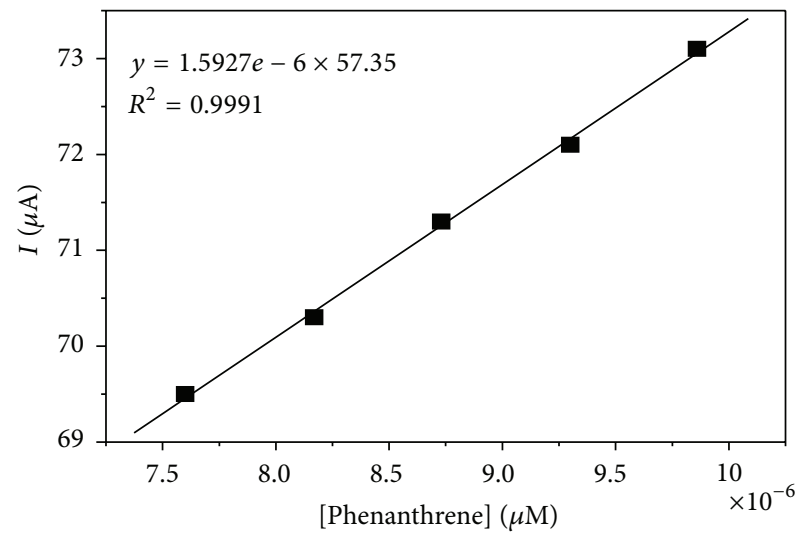

(b)

Figure 12: (a) SWV of PANI-NiO in $1 \mathrm{M} \mathrm{HCl}$ containing different concentration of phenanthrene. (b) The plot of current (I) against phenanthrene concentration.

may probably present in water samples along phenanthrene. Result indicates no interference from these ions at $3 \times 10^{-6} \mathrm{M}$ phenanthrene concentration.

\section{Conclusion}

This work describes the electron transport and electrocatalytic properties of chemically synthesized nickel oxide nanoparticles $(\mathrm{NiO})$ supported on PANI nanofibers. It is shown that the PANI-NiO nanocomposites modified GC electrode
(GCE-PANI-NiO) yielded the fastest electron transport as well as the best electrocatalytic behaviour towards phenanthrene compared with other electrodes investigated. The GCE-PANI-NiO electrode gave LoD of $0.732 \mathrm{pM}$ towards phenanthrene. This enhancement and low LoD is associated with high electrical-conducting PANI which forms a synergistic behaviour with nickel oxide $(\mathrm{NiO})$ nanoparticles. Electrocatalysis of phenanthrene on the PANI-NiO was predominantly diffusion-controlled, with some adsorption of reaction intermediates. 


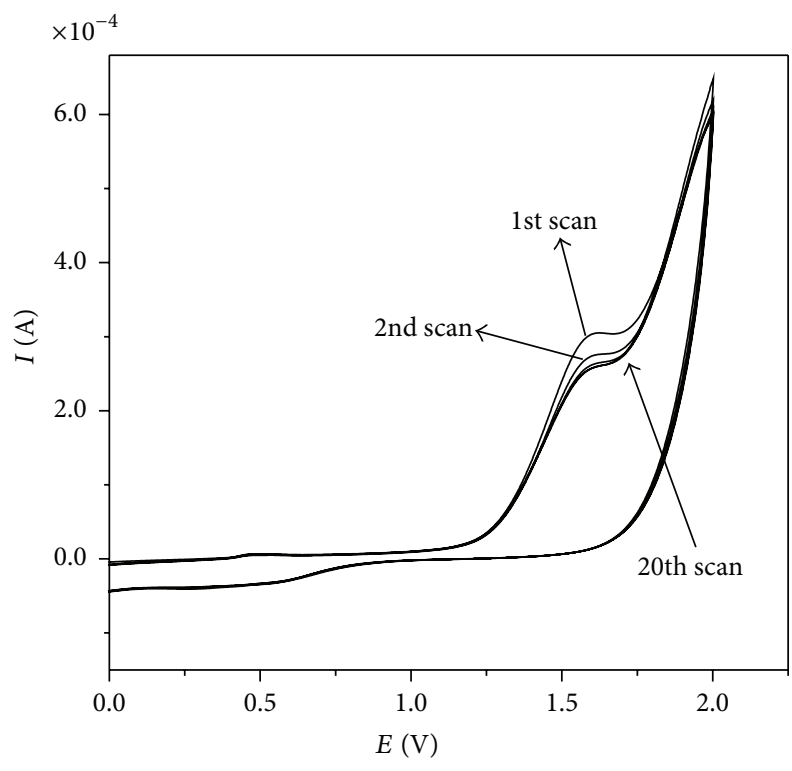

FIGURE 13: Repetitive cyclic voltammograms (20 scans) show the current response and the stability of PANI-NiO modified electrode

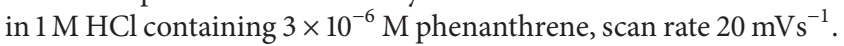

\section{Conflict of Interests}

The authors declare that there is no conflict of interests regarding the publication of this paper.

\section{Acknowledgments}

This project was supported by the North-West University (Mafikeng Campus), Material Science Innovation \& Modelling (MaSIM) Focus Area, Faculty of Agriculture, Science and Technology. Omolola E. Fayemi thanks Sasol Inzalo/National Research Foundation (NRF) for Ph.D. degree research funding. Abolanle S. Adekunle thanks the NorthWest University for postdoctoral fellowship and Obafemi Awolowo University, Nigeria, for the research leave visit. Eno E. Ebenso acknowledges the National Research Foundation of South Africa for Incentive Funding for Rated Researchers.

\section{References}

[1] A. G. MacDiarmid, "Nobel lecture: 'Synthetic metals': a novel role for organic polymers," Reviews of Modern Physics, vol. 73, no. 3, pp. 701-712, 2001.

[2] D. Li, J. Huang, and R. B. Kaner, "Polyaniline nanofibers: a unique polymer nanostructure for versatile applications," Accounts of Chemical Research, vol. 42, no. 1, pp. 135-145, 2009.

[3] H. Zhou, H. Chen, S. Luo, J. Chen, W. Wei, and Y. Kuang, "Glucose biosensors: an overview of use in clinical practice," Biosensor, Bioelectronic, vol. 20, no. 7, pp. 1305-1311, 2005.

[4] T. Yang, N. Zhou, Y. Zhang, W. Zhang, K. Jiao, and G. Li, "Synergistically improved sensitivity for the detection of specific DNA sequences using polyaniline nanofibers and multi-walled carbon nanotubes composites," Biosensors and Bioelectronics, vol. 24, no. 7, pp. 2165-2170, 2009.
[5] M. Li, Y. Guo, Y. Wei, A. G. MacDiarmid, and P. I. Lelkes, "Electrospinning polyaniline-contained gelatin nanofibers for tissue engineering applications," Biomaterials, vol. 27, no. 13, pp. 2705-2715, 2006.

[6] X. Jing, Y. Wang, D. Wu, L. She, and Y. Guo, "Polyaniline nanofibers prepared with ultrasonic irradiation," Journal of Polymer Science, Part A: Polymer Chemistry, vol. 44, no. 2, pp. 1014-1019, 2006.

[7] C.-G. Wu and T. Bein, "Conducting polyaniline filaments in a mesoporous channel host," Science, vol. 264, no. 5166, pp. 17571759, 1994.

[8] A. Abdolahi, E. Hamzah, Z. Ibrahim, and S. Hashim, "Synthesis of uniform polyaniline nanofibers through interfacial polymerization," Materials, vol. 5, no. 8, pp. 1487-1494, 2012.

[9] W. Zhong, J. Deng, Y. Yang, and W. Yang, "Synthesis of largearea three-dimensional polyaniline nanowire networks using a 'soft template,' Macromolecular Rapid Communications, vol. 26, no. 5, pp. 395-400, 2005.

[10] J. Huang, S. Virji, B. H. Weiller, and R. B. Kaner, "Polyaniline nanofibers: facile synthesis and chemical sensors," Journal of the American Chemical Society, vol. 125, no. 2, pp. 314-315, 2003.

[11] S. Virji, J. Huang, R. B. Kaner, and B. H. Weiller, "Polyaniline nanofiber gas sensors: examination of response mechanisms," Nano Letters, vol. 4, no. 3, pp. 491-496, 2004.

[12] A. Morrin, O. Ngamna, A. J. Killard, S. E. Moulton, M. R. Smyth, and G. G. Wallace, "An amperometric enzyme biosensor fabricated from polyaniline nanoparticles," Electroanalysis, vol. 17, no. 5-6, pp. 423-430, 2005.

[13] R. Garjonyte and A. Malinauskas, "Amperometric glucose biosensors based on Prussian Blue- and polyaniline-glucose oxidase modified electrodes," Biosensors and Bioelectronics, vol. 15, no. 9-10, pp. 445-451, 2000.

[14] J. J. Langer, M. Filipiak, J. Kęcińska, J. Jasnowska, J. Włodarczak, and B. Buładowski, "Polyaniline biosensor for choline determination," Surface Science, vol. 573, no. 1, pp. 140-145, 2004.

[15] T. Kuilla, S. Bhadra, D. Yao, N. H. Kim, S. Bose, and J. H. Lee, "Recent advances in graphene based polymer composites," Progress in Polymer Science, vol. 35, no. 11, pp. 1350-1375, 2010.

[16] K. Zhang, L. L. Zhang, X. S. Zhao, and J. S. Wu, "Graphene/ polyaniline nanofiber composites as supercapacitor electrodes," Chemistry of Materials, vol. 22, no. 4, pp. 1392-1401, 2010.

[17] J. Yan, T. Wei, B. Shao et al., "Preparation of a graphene nanosheet/polyaniline composite with high specific capacitance," Carbon, vol. 48, no. 2, pp. 487-493, 2010.

[18] L. Al-Mashat, K. Shin, K. Kalantar-Zadeh et al., "Graphene/ polyaniline nanocomposite for hydrogen sensing," Journal of Physical Chemistry C, vol. 114, no. 39, pp. 16168-16173, 2010.

[19] O. Tovide, N. Jaheed, N. Mohamed et al., "Graphenated polyaniline-doped tungsten oxide nanocomposite sensor for real time determination of phenanthrene," Electrochimica Acta, vol. 128, pp. 138-148, 2014.

[20] V. Vestreng and H. Klein, "Emission data reported to UNECE/ EMEP: quality assurance and trend analysis \& presentation of WebDab," MSc-W Status Report, Norwegian Meteorological Institute, Oslo, Norway, 2002.

[21] S. Xu, W. Liu, and S. Tao, "Emission of polycyclic aromatic hydrocarbons in China," Environmental Science \& Technology, vol. 40, no. 3, pp. 702-708, 2006.

[22] H. X. Yang, Q. F. Dong, X. H. Hu, X. P. Ai, and S. X. Li, "Preparation and characterization of $\mathrm{LiNiO}_{2}$ synthesized from $\mathrm{Ni}(\mathrm{OH})_{2}$ and $\mathrm{LiOH} \bullet \mathrm{H}_{2} \mathrm{O}$," Journal of Power Sources, vol. 79, no. 2, pp. 256-261, 1999. 
[23] I. Hotový, J. Huran, L. Spiess, R. Čapkovic, and Š. Haščík, "Preparation and characterization of $\mathrm{NiO}$ thin films for gas sensor applications," Vacuum, vol. 58, no. 2, pp. 300-307, 2000.

[24] E. L. Miller and R. E. Rocheleau, "Electrochemical behavior of reactively sputtered iron-doped nickel oxide," Journal of the Electrochemical Society, vol. 144, no. 9, pp. 3072-3077, 1997.

[25] G. Wang, X. Lu, T. Zhai et al., "Free-standing nickel oxide nanoflake arrays: synthesis and application for highly sensitive non-enzymatic glucose sensors," Nanoscale, vol. 4, no. 10, pp. 3123-3127, 2012.

[26] Y. Ichiyanagi, N. Wakabayashi, J. Yamazaki et al., "Magnetic properties of NiO nanoparticles," Physica B: Condensed Matter, vol. 329-333, part 2, pp. 862-863, 2003.

[27] S. A. Makhlouf, F. T. Parker, F. E. Spada, and A. E. Berkowitz, "Magnetic anomalies in $\mathrm{NiO}$ nanoparticles," Journal of Applied Physics, vol. 81, no. 8, pp. 5561-5563, 1997.

[28] S. Chakrabarty and K. Chatterjee, "Synthesis and characterization of nano dimensional nickelous oxide $(\mathrm{NiO})$ semiconductor," Journal of Physical Science, vol. 13, pp. 245-250, 2009.

[29] A. S. Adekunle, S. Lebogang, P. L. Gwala et al., "Electrochemical response of nitrite and nitric oxide on graphene oxide nanoparticles doped with Prussian blue (PB) and $\mathrm{Fe}_{2} \mathrm{O}_{3}$ nanoparticles," RSC Advances, vol. 5, no. 35, pp. 27759-27774, 2015.

[30] N. G. R. Mathebe, A. Morrin, and E. I. Iwuoha, "Electrochemistry and scanning electron microscopy of polyaniline/ peroxidase-based biosensor," Talanta, vol. 64, no. 1, pp. 115-120, 2004.

[31] G.-F. Cai, J.-P. Tu, J. Zhang et al., "An efficient route to a porous $\mathrm{NiO} /$ reduced graphene oxide hybrid film with highly improved electrochromic properties," Nanoscale, vol. 4, no. 18, pp. 57245730, 2012.

[32] D. Giovanelli, N. S. Lawrence, S. J. Wilkins, L. Jiang, T. G. J. Jones, and R. G. Compton, "Anodic stripping voltammetry of sulphide at a nickel film: towards the development of a reagentless sensor," Talanta, vol. 61, no. 2, pp. 211-220, 2003.

[33] J. Zagal, M. Páez, A. A. Tanaka, J. R. dos Santos Jr., and C. A. Linkous, "Electrocatalytic activity of metal phthalocyanines for oxygen reduction," Journal of Electroanalytical Chemistry, vol. 339, no. 1-2, pp. 13-30, 1992.

[34] Q.-Z. Yu, M.-M. Shi, M. Deng, M. Wang, and H.-Z. Chen, "Morphology and conductivity of polyaniline sub-micron fibers prepared by electrospinning," Materials Science and Engineering $B$, vol. 150, no. 1, pp. 70-76, 2008.

[35] D. A. Li, A. Babel, A. Sanson, Y. Jenekhe, and N. Xia, "Nanofibers of conjugated polymers prepared by electrospinning with a two-capillary spinneret," Advanced Materials, vol. 16, pp. 2062-2066, 2004.

[36] S. Xing, C. Zhao, S. Jing, and Z. Wang, "Morphology and conductivity of polyaniline nanofibers prepared by 'seeding' polymerization," Polymer, vol. 47, no. 7, pp. 2305-2313, 2006.

[37] A. S. Adekunle and K. I. Ozoemena, "Electron transport and electrocatalytic properties of MWCNT/nickel nanocomposites: hydrazine and diethylaminoethanethiol as analytical probes," Journal of Electroanalytical Chemistry, vol. 645, no. 1, pp. 41-49, 2010.

[38] X. H. Xia, J. P. Tu, J. Zhang, X. L. Wang, W. K. Zhang, and $\mathrm{H}$. Huang, "A highly porous $\mathrm{NiO}$ /polyaniline composite film prepared by combining chemical bath deposition and electro-polymerization and its electrochromic performance," Nanotechnology, vol. 19, no. 46, Article ID 465701, 2008.
[39] D. Geng, N. Ding, T. S. Andy Hor, Z. Liu, X. Sun, and Y. Zong, "Potential of metal-free 'graphene alloy' as electrocatalysts for oxygen reduction reaction," Journal of Materials Chemistry A, vol. 3, no. 5, pp. 1795-1810, 2015.

[40] Y.-K. Sun, M. Ma, Y. Zhang, and N. Gu, "Synthesis of nanometer-size maghemite particles from magnetite," Colloids and Surfaces A: Physicochemical and Engineering Aspects, vol. 245, no. 1-3, pp. 15-19, 2004.

[41] A. Morrin, O. Ngamna, A. J. Killard, S. E. Moulton, M. R. Smyth, and G. G. Wallace, "An amperometric enzyme biosensor fabricated from polyailine nanoparticles," Electroanalysis, vol. 17, no. 5-6, pp. 423-430, 2005.

[42] V. Somerset, J. Leaner, R. Mason, E. Iwuoha, and A. Morrin, "Development and application of a poly $(2,2$ '-dithiodianiline) (PDTDA)-coated screen-printed carbon electrode in inorganic mercury determination," Electrochimica Acta, vol. 55, no. 14, pp. 4240-4246, 2010.

[43] M. Hasanzadeh, B. Khalilzadeh, N. Shadjou et al., "A new kinetic-mechanistic approach to elucidate formaldehyde electrooxidation on copper electrode," Electroanalysis, vol. 22, no. 2, pp. 168-176, 2010.

[44] A. J. Bard and L. R. Faulkner, Electrochemical Methods: Fundamentals and Applications, John Wiley \& Sons, New York, NY, USA, 2nd edition, 2001.

[45] B. A. Boukamp, "A Nonlinear Least Squares Fit procedure for analysis of immittance data of electrochemical systems," Solid State Ionics, vol. 20, no. 1, pp. 31-44, 1986.

[46] G. Nurk, H. Kasuk, K. Lust, A. Janes, and E. Lust, "Adsorption kinetics of dodecyl sulfate anions on the bismuth plane," Journal of Electroanalytical Chemistry, vol. 553, pp. 1-19, 2003.

[47] S. Radhakrishnan, K. Krishnamoorthy, C. Sekar, J. Wilson, and S. J. Kim, "A highly sensitive electrochemical sensor for nitrite detection based on $\mathrm{Fe}_{2} \mathrm{O}_{3}$ nanoparticles decorated reduced graphene oxide nanosheets," Applied Catalysis B: Environmental, vol. 148-149, pp. 22-28, 2014.

[48] Z. Xu, N. Gao, H. Chen, and S. Dong, "Biopolymer and carbon nanotubes interface prepared by self-assembly for studying the electrochemistry of microperoxidase-11," Langmuir, vol. 21, no. 23, pp. 10808-10813, 2005.

[49] B. Agboola and T. Nyokong, "Comparative electrooxidation of nitrite by electrodeposited $\mathrm{Co}(\mathrm{II}), \mathrm{Fe}(\mathrm{II})$ and $\mathrm{Mn}$ (III) tetrakis (benzylmercapto) and tetrakis (dodecylmercapto) phthalocyanines on gold electrodes," Analytica Chimica Acta, vol. 587, no. 1, pp. 116-123, 2007.

[50] C. Rassie, R. A. Olowu, T. T. Waryo et al., "Dendritic 7Tpolythiophene electro-catalytic sensor system for the determination of polycyclic aromatic hydrocarbons," International Journal of Electrochemical Science, vol. 6, no. 6, pp. 1949-1967, 2011.

[51] S. Radhakrishnan, C. R. K. Rao, and M. Vijayan, "Performance of conducting polyaniline-DBSA and polyaniline-DBSA/ $\mathrm{Fe}_{3} \mathrm{O}_{4}$ composites as electrode materials for aqueous redox supercapacitors," Journal of Applied Polymer Science, vol. 122, no. 3, pp. 1510-1518, 2011.

[52] M. Wei, S. Duan, S. Liu, X. Zheng, F. Xia, and C. Zhou, "Electrochemical determination of phenanthrene based on anthraquinone sulfonate and poly diallyldimethylammonium chloride modified indium-tin oxide electrode," RSC Advances, vol. 5, no. 60, pp. 48811-48815, 2015. 

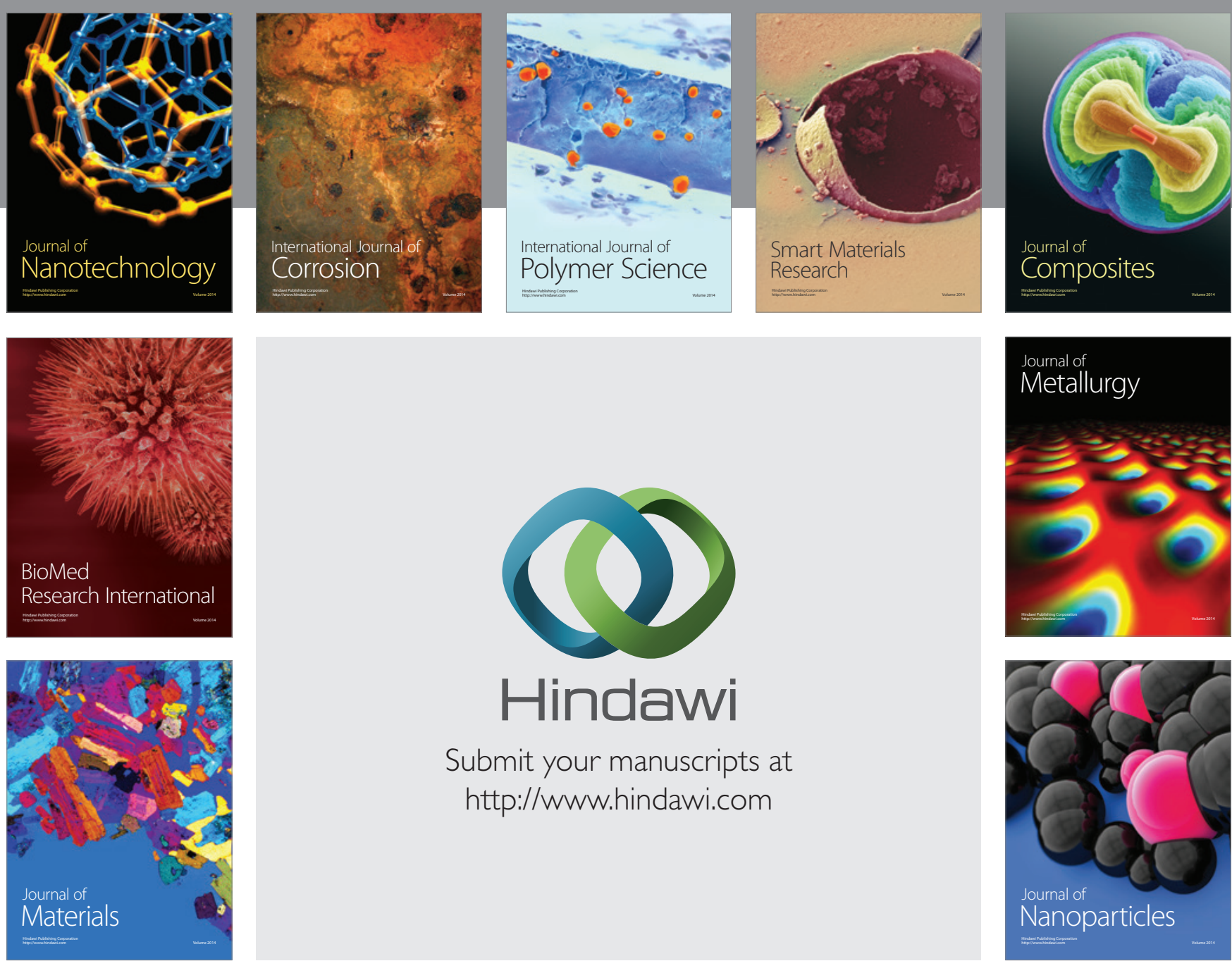

\section{Hindawi}

Submit your manuscripts at

http://www.hindawi.com

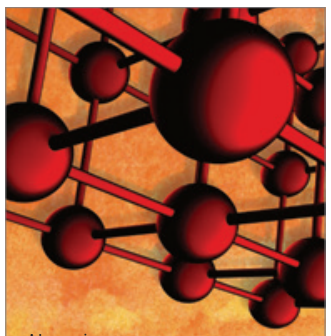

Materials Science and Engineering
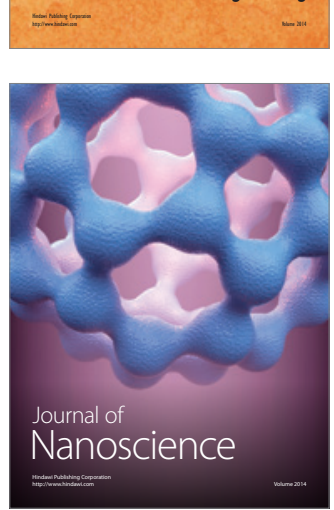
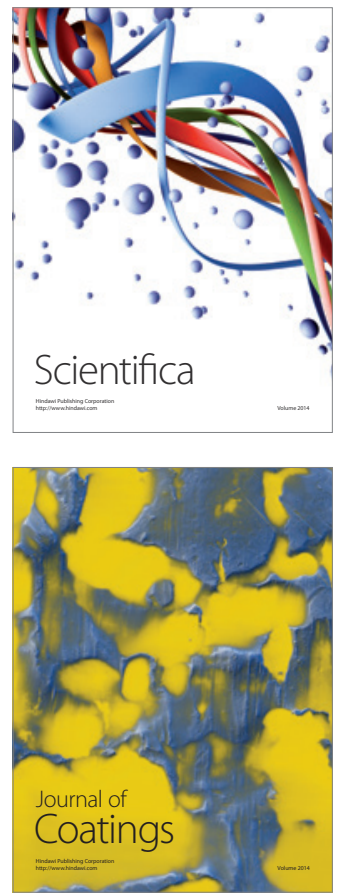
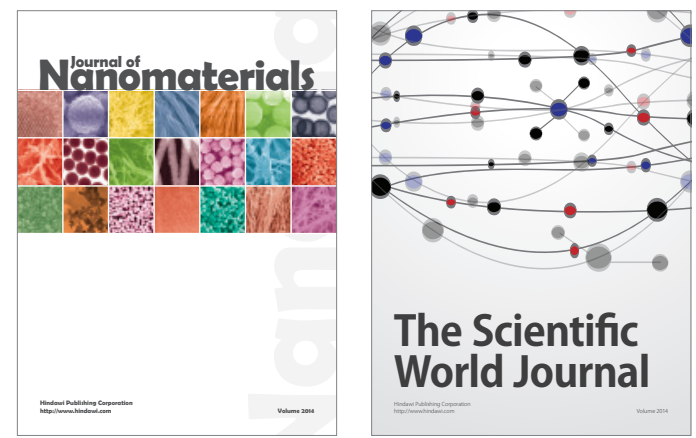

The Scientific World Journal
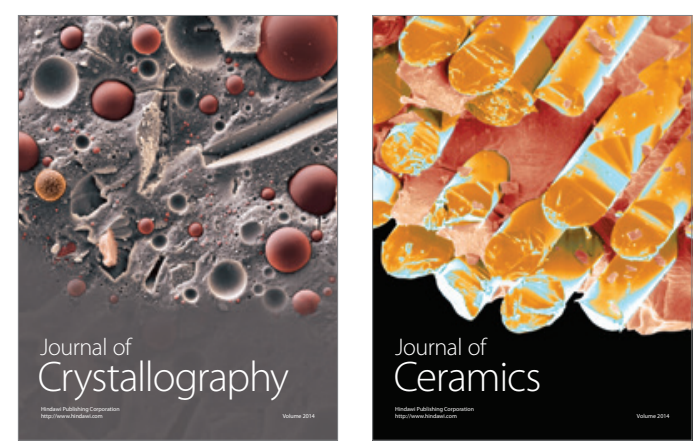
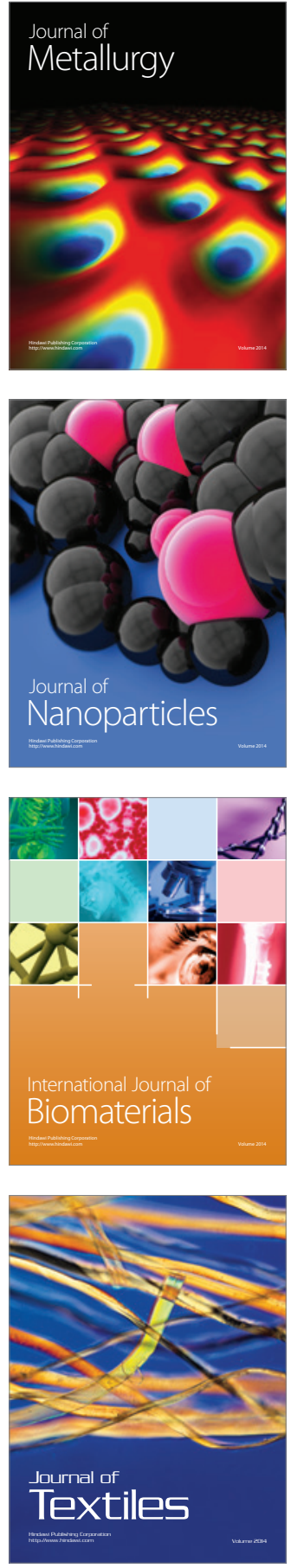